Rabaska

Revue d'ethnologie de l'Amérique française

\title{
Margaret Low (1941-2020)
}

\section{Jean-Pierre Pichette}

Volume 18, 2020

URI : https://id.erudit.org/iderudit/1072923ar

DOI : https://doi.org/10.7202/1072923ar

Aller au sommaire du numéro

Éditeur(s)

Société québécoise d'ethnologie

ISSN

1703-7433 (imprimé)

1916-7350 (numérique)

Découvrir la revue

Citer ce document

Pichette, J.-P. (2020). Margaret Low (1941-2020). Rabaska, 18, 303-305.

https://doi.org/10.7202/1072923ar

Ce document est protégé par la loi sur le droit d'auteur. L'utilisation des services d'Érudit (y compris la reproduction) est assujettie à sa politique d'utilisation que vous pouvez consulter en ligne.

https://apropos.erudit.org/fr/usagers/politique-dutilisation/
Cet article est diffusé et préservé par Érudit.

Érudit est un consortium interuniversitaire sans but lucratif composé de l’Université de Montréal, l'Université Laval et l'Université du Québec à Montréal. Il a pour mission la promotion et la valorisation de la recherche. https://www.erudit.org/fr/ 


\section{Margaret Low (1941-2020)}

Née à Toronto (East York) le 23 juin 1941, Margaret Jean Low est décédée à Grimsby, en Ontario, le 7 mai 2020. Chercheuse méticuleuse et modeste, elle a laissé sa marque dans le domaine du conte populaire en association étroite avec son maître Luc Lacourcière.

Après ses études élémentaires et secondaires, elle s'inscrit à l'Université de Toronto; elle y termine son baccalauréat en juin 1964 puis entreprend des études supérieures en français au niveau de la maîtrise qu'elle obtient en 1966. Pour perfectionner la connaissance de cette langue, elle avait fait deux séjours d'immersion dans une famille aux îles Saint-Pierre-etMiquelon, grâce à l'école d'été que cette

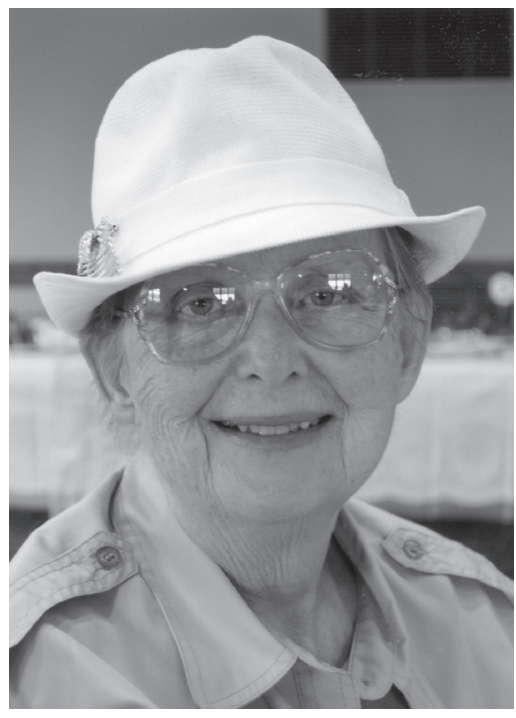

Margaret Low

Photo : famille Edward Low université y organisait, et même suivi un cours en France. Mais le semestre de l'hiver 1966 devait chambarder complètement sa vie.

Cette année-là, l'Université de Toronto inaugurait une chaire d'études canadiennes et, pour ce faire, on avait invité le professeur Luc Lacourcière de l'Université Laval. Or, il mit au programme, de janvier à avril, un cours sur la littérature orale au Canada français. Quand la jeune étudiante comprit que « la matière de son cours serait celle du conte populaire », la confusion fut totale. D'emblée «sceptique, voire même choquée », elle était consternée à la pensée « qu'un homme qui avait la réputation de savant et d'homme de lettres pût non seulement perdre son temps, mais voulût même nous faire perdre le nôtre - à nous qui avions coutume d'étudier des matières sérieuses comme l'histoire, les littératures et les langues -, en traitant d'un sujet aussi enfantin et frivole que les "contes de bonnes femmes" ». Comment « oser parler de contes » dans une enceinte universitaire ! pensa-t-elle. 
Son trouble serait cependant de courte durée : « À ma grande surprise, dès le premier cours, j'ai succombé, comme les autres étudiants d'ailleurs, au charme de cette matière aussi bien qu'à l'enthousiasme du professeur. » Elle traduira plus tard sa réaction ainsi : «j'ai peu à peu retrouvé dans la littérature orale des traits humains qui faisaient défaut, à mon avis, dans mes études antérieures ». Cette révélation la marqua «à un tel point, confiera-telle, que j'ai quitté l'Université de Toronto pour poursuivre mes études de

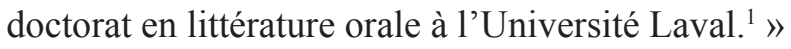

Margaret Low passera environ 25 ans auprès de Luc Lacourcière ${ }^{2}$. Lui qui maitrisait l'art d'apparier le type d'un conte à l'étudiant qui allait l'analyser, amena la doctorante anglophone à l'étude d'un conte rare du cycle de l'épouse bannie, inconnu sous cette forme en France et peu répandu ailleurs dans le monde : le type 708A* (462) qu'elle nommera «L'Oiseau mystérieux du château volant » dans sa thèse, soutenue en novembre 1978, mais restée inédite $^{3}$. Néanmoins, dans un court article traitant du principe de vie externe, motif présent dans plusieurs contes merveilleux, elle avait résumé ce type et noté qu'on l'avait alors « recueilli 34 fois au Canada français, mais qu'il n'avait apparemment jamais été trouvé en France ni en Irlande »; d'autre part, il offrait curieusement des accointances plus près des récits du type 462 attestés en Inde tandis que les quelques versions de langues romanes (espagnoles, italiennes ou celle chilienne) s'en écartaient sensiblement ${ }^{4}$.

Tout en poursuivant à l'Université Laval ses études sur le conte au niveau postdoctoral, elle collaborera à divers projets touchant la littérature orale : membre de l'équipe chargée du grand «Inventaire des traditions populaires des francophones en Amérique du Nord », grâce à une bourse Killam obtenue par Luc Lacourcière en 1971, elle participera aussi à l'établissement des « Corpus de faits ethnographiques » des régions du Québec dirigés par Jean-Claude Dupont dans les années 1980, et à l'édition d'anthologies, particulièrement en cosignant une série de contes et légendes dans Folktales Told around the World de Richard Dorson ${ }^{5}$, et Héritage de la francophonie canadienne. Traditions orales de Jean-Claude Dupont ${ }^{6}$.

1. Margaret Low, «Luc Lacourcière et le conte populaire », dans Jean-Claude Dupont (dir.), Mélanges en l'honneur de Luc Lacourcière, Folklore français d'Amérique, Montréal, Leméac, 1978, p. 49.

2. Notons qu'en 1968 elle s'initia au terrain en menant des enquêtes sur les traditions orales auprès des anciens dans des réserves amérindiennes du nord de l'Ontario.

3. Id., "L'Oiseau mystérieux du château volant : monographie internationale du contetype 708A* (462) », Université Laval, Thèse Ph.D., 1978, xxvi-473 p.

4 Id., "The Motif of the External Soul in French Canadian Folktales », dans Revue de l'Université Laurentienne, vol. 8, $\mathrm{n}^{\circ}$ 2, février 1976, p. 61-68.

5. Luc Lacourcière et Margaret Low, « Canadian Folktales and Legends from Quebec and Acadia ", dans Richard M. Dorson (dir.), Folktales Told around the World, Chicago \& London, University of Chicago Press, 1975, p. 429-467.

6. Jean-Claude Dupont (dir.), Héritage de la francophonie canadienne. Traditions orales, 
Passionnée par la recherche plus que l'enseignement, elle s'attachera autant aux travaux de Luc Lacourcière, qu'elle rassemblera et ordonnera pour les archives, qu'à l'homme lui-même, avec qui elle vivra dans sa maison de Beaumont. En terminant l'hommage qu'elle rendait à son maître en 1978, elle reconnaissait avoir été " parmi les centaines qui ont eu le privilège de suivre ses cours, [...] parmi la centaine qui a eu l'avantage de l'avoir pour directeur de thèse ", mais, par-dessus tout, elle tenait à le remercier " de tout cœur » pour « l'honneur tout spécial de l'assister dans la préparation du Catalogue raisonné du conte populaire français en Amérique du Nord ${ }^{7}$ ».

Quelques années après la mort de Luc Lacourcière survenue en 1989, elle dut rentrer à Toronto pour prendre soin de ses parents, mais elle conserva toujours des liens étroits avec des amis de Laval. Celle qui assurait qu' " on trouve toute la vie dans les contes » et que Luc Lacourcière considérait, en raison de sa grande discrétion et de son amour du conte, comme « l'oiseau mystérieux du château volant », n'aura pu achever l'édition du tome premier du catalogue, consacré aux contes d'animaux. Récemment, quelques amis de Margaret Low et Luc Lacourcière ont convenu de reprendre le flambeau et de parachever ce volume ${ }^{8}$.

Jean-Pierre Pichette 9 Société québécoise d'ethnologie

Québec, Presses de l'Université Laval, 1986 ; responsable de la section « Contes », p. 183-266.

7. Margaret Low, « Luc Lacourcière et le conte populaire », op. cit., p. 57.

8. « Le Catalogue raisonné du conte populaire français en Amérique du Nord. Les contes d'animaux » par Luc Lacourcière et Margaret Low, 1981.

9. La préparation de cette note doit beaucoup à la chronologie inédite compilée par Jean Du Berger, « Pour une histoire des études de folklore à l’Université Laval (1936-1986) », 144 p. ; des éléments biographiques proviennent de son frère, Edward Low, ainsi que de son amie, Jeanne Pomerleau. 